\title{
Fatores Mediadores da Aprendizagem na Educação a Distância em Administração Pública
}

Mediating Factors of Learning in Distance Education in Public Management

Factores Medidores del Aprendizaje en la Educación a Distancia en Administración Publica

\author{
Jammilly Mikaela Fagundes Brandão \\ Doutoranda em Administração, no Programa de Pós-Graduação em Administração - PPGA/UFPB \\ Estudante - Universidade Federal da Paraíba \\ http://lattes.cnpq.br/6253114974936219 \\ http://orcid.org/0000-0002-8826-9762 \\ jammillybrandao@gmail.com
}

Anielson Barbosa da Silva Pós-Doutorado em Psicologia - Universidade de Valência/Espanha (em andamento) Professor do Departamento de Administração da Universidade Federal da Paraíba - UFPB http://lattes.cnpq.br/3405428972303042 http://orcid.org/0000-0002-6549-9733 anielson@uol.com.br

Resumo: Este estudo tem como objetivo identificar os fatores mediadores da aprendizagem na educação a distância em administração pública vinculados ao Programa Nacional de Administração Pública - PNAP. Na fundamentação teórica é apresentada a aprendizagem de adultos com base na abordagem andragógica, incluindo o modelo andragógico desenvolvido por Knowles, Holton e Seanson (2011). A pesquisa é quantitativa e de caráter descritivo, tendo utilizado o método survey aplicado a 273 estudantes de 10 instituições de ensino superior de diferentes estados brasileiros. Os resultados possibilitaram a identificação de seis princípios andragógicos que caracterizam o processo de aprendizagem, bem como a existência de fatores mediadores do processo de aprendizagem associados às diferenças individuais dos aprendizes. Tais princípios envolvem um processo de desenvolvimento pessoal que está intimamente ligado à experiência, que pode tornar os alunos mais abertos à mudança e interessados em aprender, como também pode torná-los mais resistentes ou desinteressados no processo de aprendizagem.

Palavras-chave: Educação de Adultos, Andragogia, Ensino Superior, Experiência.

\begin{abstract}
This study aims to identify the mediating factors of learning in distance education in public administration linked to the National Program for Public Management-PNAP in Brazil. The theoretical basis presents adult learning based on the andragogical approach, including the andragogical model developed by Knowles, Holton and Seanson (2011).The research is quantitative and descriptive and it was used the survey method applied to 273 students from 10 institutions of higher education in different states of Brazil. The results allowed the identification of six andragogical principles that characterize the learning process as well as the existence of mediating factors of the learning process associated with the individual differences of the apprentices. These principles involve a process of personal development that is closely linked to the experience, which can make students more open to change and more interested in learning or make them more resistant to or uninterested in the learning process.
\end{abstract}

Keywords: Adult Education, Andragogy, Higher Education, Experience.
Resumen: Este estudio tiene como objetivo identificar los factores mediadores del aprendizaje en la educación a distancia en administración pública vinculados al Programa Nacional de Administración Pública - PNAP. En la fundamentación teórica se presenta el aprendizaje de adultos con base en el enfoque andragógico, incluyendo el modelo andragógico desarrollado por Knowles, Holton y Seanson (2011). La investigación es cuantitativa y de carácter descriptivo, habiendo utilizado el método survey aplicado a 273 estudiantes de 10 instituciones de enseñanza superior de diferentes estados brasileños. Los resultados posibilitaron la identificación de seis principios andragógicos que caracterizan el proceso de aprendizaje, así como la existencia de factores mediadores del proceso de aprendizaje asociados a las diferencias individuales de los aprendices. Estos principios implican un proceso de desarrollo personal que está íntimamente ligado a la experiencia, que pueden hacerlos más abiertos al cambio e interesados en aprender, como también puede hacerlos más resistentes o desinteresados en el proceso de aprendizaje.

Palabras clave: Educación de Adultos, Andragogia, Enseñanza Superior, Experiencia.

Texto completo em português: http://www.apgs.ufv.br

Full text in Portuguese: http://www.apgs.ufv.br

\section{Introdução}

A educação a distância $(\mathrm{EaD})$ tem ocupado um lugar expressivo na sociedade do conhecimento (Laruccia, Almeida, \& Ruiz, 2010). O número de cursos a distância em nível de graduação e pósgraduação universitária vem crescendo no Brasil. Segundo dados do Censo da Educação Superior de 2010, dentre as matrículas de graduação, incluindo cursos de licenciatura, bacharelado e tecnológicos, no ensino superior do país, a EaD corresponde a 14,6\% (Cieglinski, 2011).

Ainda com base nos dados de 2011 do Ministério da Educação, existem 6.379.299 alunos em 2.377 instituições de ensino superior, que oferecem 29.507 cursos, sendo o curso de Administração o primeiro no ranking (Cieglinski, 2011; Reymão, s./d.). Destaca-se ainda que embora as matrículas continuem concentradas nas instituições privadas $(74 \%)$, houve um crescimento significativo no número de alunos das escolas públicas (12\%) (Cieglinski, 2011).

Buscando ampliar ainda mais as possibilidades de acesso à educação superior, tornando-a mais democrática e igualitária, o Governo Federal institucionalizou o Programa Nacional de Formação em Administração Pública - PNAP, que tem como finalidade ofertar cursos gratuitos e de qualidade na área de administração, em nível de graduação e pós-graduação, na modalidade a distância. O objetivo do PNAP é a formação de 
profissionais com amplo conhecimento em administração pública para atuar no âmbito federal, estadual e municipal, administrando com competência e ética organizações governamentais e não governamentais (Demarco, 2013).

Coll, Mauri e Onrubia (2010) enfatizam que as Tecnologias de Informação e Comunicação são possuidoras de alto potencial e aplicabilidade a processos de aprendizagem colaborativo, ao situar o estudante no centro do processo de aprendizagem, democratizar os espaços de interação e ação entre os diferentes atores, e, principalmente, fortalecer a autonomia dos estudantes. No entanto, a qualidade da educação em ambiente virtual está associada às condições proporcionadas pelas instituições que ofertam essa modalidade de ensino, tais como capacidade tecnológica, materiais didáticos, metodologias utilizadas e qualificação dos docentes (Schnitman, 2011). Nesse contexto, o conhecimento do perfil do aluno virtual pode ampliar a utilização das tecnologias da informação em benefício da aprendizagem, auxiliando na consolidação de práticas significativas de educação em ambiente virtual (Smith, 2002).

Da mesma forma, o processo de formação dos alunos de administração pública na modalidade a distância é influenciado por uma série de fatores. Além do perfil e variáveis intrínsecas ao aluno, existem alguns fatores mediadores contextuais, como a metodologia utilizada no curso, a estrutura e a organização do ambiente virtual, e a relação do aluno com os demais agentes envolvidos no processo de aprendizagem, como o professor e o tutor. No entanto, compreender como ocorre o processo de aprendizagem e conhecer o perfil do aluno inserido nesta modalidade de ensino pode ajudar a aperfeiçoar o processo e a formação do administrador nesse ambiente.

Para ampliar a compreensão sobre 0 processo de aprendizagem na formação de administradores no contexto da educação a distância, surgiu o interesse em desenvolver um estudo balizado pela abordagem andragógica. Com efeito, este estudo aborda o processo de aprendizagem e o ensino a distância de administração pública, com base nos princípios centrais da andragogia propostos por Knowles, Holton e Swanson (2011). Sob essa perspectiva, busca responder a seguinte questão: Quais os fatores mediadores do processo de aprendizagem de alunos de cursos de graduação a distância em administração pública?

Nesse sentido, o objetivo principal deste trabalho é identificar os fatores mediadores da aprendizagem de alunos de cursos de graduação a distância em administração pública vinculados ao PNAP. A próxima seção discute a base teórica utilizada para compreender o fenômeno.

\section{Referencial Teórico}

A andragogia busca auxiliar e compreender o processo de aprendizagem dos adultos (Ferraz, Lima, \& Silva, 2004; Knowles, 1975). Refere-se a uma teoria cuja aprendizagem é centrada no aluno. Knowles (1980, p. 43) define-a como "a arte e a ciência de ajudar adultos a aprenderem". Considerando que os adultos possuem necessidades individuais a serem alcançadas por meio do aprendizado, a andragogia fundamenta-se em elementos como o desenvolvimento da reflexão crítica, a aprendizagem por meio das experiências e a melhoria do ambiente de aprendizagem para facilitar a aquisição de conhecimentos e troca de experiências (Freire, 1987).

De acordo com Cavalcanti (1999), estudantes universitários não são exatamente adultos, mas estão próximos desta fase de suas vidas. Dessa forma, ao ofertar a estes um ensino centrado no professor, pode-se acarretar em um retardamento da maturidade, pois coloca-os em total dependência dos professores, sem estimular o desenvolvimento do autodirecionamento e da responsabilidade sobre sua aprendizagem.

Conforme Mezirow (1991), as pessoas vão aprimorando seu aprendizado à medida que adquirem experiência e, assim, a aprendizagem é baseada na interpretação e exposição das experiências vivenciadas pelo indivíduo, que são determinantes para as suas ações, expectativas, bem-estar e desempenho. Dewey (1973) já considerava o aspecto experiencial em seus estudos ao ressaltar que os indivíduos vivem, experimentam e aprendem concomitantemente.

Aliada àimportância das experiências está a relevância de características de autodirecionamento dos alunos. Entende-se por autodirecionamento o processo em que o próprio aprendiz despende esforços para localizar os recursos necessários para a sua aprendizagem, assumindo um papel ativo nas experiências que possam contribuir para o seu crescimento, assim como no diagnóstico e na avaliação da construção desse processo (Cranton, 2006; Brookfield, 1986).

Levando em consideração que a aprendizagem é facilitada quando o aluno participa responsavelmente do seu processo de construção (Rogers, 1969), o modelo andragógico proposto por Knowles, Holton e Swanson (2011) pode ser visualizado como uma adequação necessária na educação para atender ao novo contexto da sociedade contemporânea, temática discutida na próxima seção.

\section{O modelo andragógico de aprendizagem}

O modelo da andragogia na prática desenvolvida por Knowles, Holton e Swanson (2011) consiste em três dimensões: (a) objetivos e propósitos para o aprendizado, que podem consistir no crescimento individual, institucional ou social; (b) diferenças individuais e situacionais, considerando as particularidades contextuais no momento da escolha da estratégia de aprendizagem; (c) princípios andragógicos, que compreendem a necessidade de saber do aprendiz, o autoconceito (aprendizagem autodirecionada), a experiência prévia, a prontidão para aprender, a orientação para a aprendizagem, e a motivação.

O primeiro princípio andragógico envolve a necessidade de saber do aprendiz, poisos adultos precisam compreender o propósitodoaprendizado antes de começarem a de fato aprender. Para Carl Rogers (1969), a aprendizagem é significativa quando o aluno percebe a relevância do que será aprendido. Evidencia-se ainda que, quando a decisão por aprender algo parte do próprio indivíduo, há um investimento maior de esforço, tanto nos 
benefícios da aprendizagem, como nas consequências negativas da nãoaprendizagem. Logo, o facilitador da aprendizagem de adultos tem como atividade primária ajudar os aprendizes a se conscientizarem da necessidade de aprender, que compreende três dimensões: a compreensão de como a aprendizagem será conduzida, o que será aprendido, e o porquê que ela é importante (Knowles, Holton, \& Swanson, 2011).

O segundo princípio da andragogia refere-se ao autoconceito do aprendiz quanto à responsabilidade de suas ações e decisões. Conforme os autores, quando o aprendiz desenvolve esse autoconceito, vai perdendo a necessidade de reconhecimento por terceiros, e se mostra resistente a situações de imposição. A autoaprendizagem é uma maneira de aprender, na qual o aluno por meio de iniciativa própria se responsabiliza pela sua aprendizagem, ao invés de esperar que terceiros determinem o quêe como ele irá aprender (Merriam, Caffarella, \& Baumgartner, 2006; JamesGorndon, Young, \& Bal, 2003; Candy,1987; Brookfield, 1986; Mezirow, 1985).

O terceiro princípio andragógico envolve o papel das experiências do aprendiz em seu processo de aprendizagem. Sobre esse aspecto, considera-se que,em função dos adultos terem vivenciado um número maior e diversificado de experiências (Merriam, Caffarella, \& Baumgartner, 2006; Kolb, 1984), a educação desses deve utilizar estratégias de ensino e aprendizagem com um enfoque na individualização, em que o próprio aprendiz é protagonista da aprendizagem. Para isso, pode-se utilizar estratégiasde ensino ativas como discussões de grupo, exercício de simulação, atividades que envolvam resolução de problemas, estudos de casos, entre outras que explorem a própria experiência do aprendiz (Knowles, Holton, \& Swanson, 2011).

Merriam, Caffarella e Baumgartner (2006) observam que as pessoas carregam um conjunto de esquemas que refletem as suas experiências, denominado por Kolb (1984) de "reservatórios de experiências" ou "loja de lembranças na mente", que é a base para assimilar novas informações. É importante observar que abagagem experiencial pode contribuir para a efetividade da aprendizagem, mas também pode se refletir de modo negativo, caso o adulto desenvolva hábitos mentais ou predisposições que o tornem resistente a novos modelos e abordagens (Schön, 1987; Argyris, 1982). Ao perceber esse conflito, é responsabilidade do educador desenvolver maneiras que ajudem o aprendiz a reavaliar sua postura, assim como auxiliá-lo para a aceitabilidade de novas abordagens (Knowles, Holton, \& Swanson, 2011). Nesse caso, o processo de "desaprender" é tão importante quanto o processo de aquisição de um novo aprendizado.

O quarto princípio andragógico diz respeito à prontidão do adulto para aprender, que se relaciona à necessidade de saber do indivíduo e à sua situação de vida. Assim, defende-se o pressuposto de que quanto mais os educadores entenderem sobre a situação de vida e a prontidão para aprender de seus alunos, mais efetiva será a aprendizagem. Todavia, destaca-se a característica situacional da aprendizagem, isto é, o aprendiz pode ter diferentes comportamentos em distintos momentos do processo, podendo, em algumas situações, atuar de forma autodirecionada e, em outras, dependente, ou seja, há variações do grau de dependência, que reflete na alta ou baixa necessidade de direção (necessidade de assistência por outra pessoa) e suporte (apoio afetivo de terceiros) (Knowles, Holton, \& Swanson, 2011).

O quinto princípio trata da orientação para aprendizagem dos adultos,que é voltada para a solução de problemas. Os adultos se sentem motivados a aprender quando percebem que o aprendizado irá ajudá-los na resolução de um problema, na execução de uma tarefa ou em lidar com as situações diárias. Acredita-se que a aprendizagem se torna mais significativa quando aplicada às situações da vida real. Assim, a abordagem experiencial passou a ser considerada fundamental na prática da aprendizagem de adultos (Knowles, Holton, \& Swanson, 2011; Jarvis, 2006; Kolb, 1984).

O último princípio andragógico refere-se à motivação para aprender. O modelo andragógico considera que, devido a pressões internas, como o desejo de aumentar a satisfação no trabalho, de maximizar a autoestima e melhorar a qualidade de vida, o aprendiz adulto apresenta-se mais motivado para aprender. Embora não se desconsidere as motivações externas como uma melhor opção de emprego, aumento salarial, promoção de cargo, entre outros, evidencia-se que, no adulto, as motivações internas são as mais significativas.Knowles, Holton e Swanson (2011) enfatizam que os adultos ficam mais motivados quando acreditam que podem aprender um novo conteúdo e que este ajudará a resolver problemas importantes na sua vida.

O desenvolvimento de capacidades de aprendizagem autodirecionada parece ser um dos principais objetivos no âmbito da educação de adultos (Knowles, Holton, \& Swanson, 2011; Brookfield, 1986). Assim, destaca-se a importância da promoção de condições libertadoras nesse contexto, para impulsionar a autonomia e o autodirecionamento nos alunos universitários, em especial de administração, que atuarão no mundo do trabalho na gestão de organizações, sejam elas públicas, privadas ou do terceiro setor.

Brandão, Cavalcante e Temoteo (2015), desenvolveram um estudo tendo como base o modelo andragógico desenvolvido por Knowles, Holton e Seanson (2011). Nessa pesquisa, as autoras buscaram analisar o nível de autodirecionamento (autonomia e independência) desses alunos em seu processo de aprendizagem com base nos princípios andragógicos descritos anteriormente: necessidade de saber do aprendiz, conceito de si do aprendiz, experiência prévia do aprendiz, prontidão para aprender, orientação para aprendizagem, e motivação para aprender. Por meio de uma survey com 60 discentes dos cursos presenciais de hotelaria e turismo da Universidade Federal da Paraíba - UFPB, constatou-se que os alunos, em suas próprias percepções, possuem características como autonomia e autodirecionamento e apresentam níveis de independência enquanto sujeitos em processo de formação e de desenvolvimento de competências. Embora esse estudo tenha sido realizado com alunos de cursos 
presenciais, caracteriza uma ratificação do modelo andragógico no ensino superior.

\section{Procedimentos Metodológicos}

Para viabilizar a consecução dos objetivos, foi realizada uma pesquisa do tipo quantitativa (Soares, \&Castro, 2012), inferencial de caráter descritivo (Sampieri, Collado, \&Lucio, 1991; Gil, 2007), utilizando o método survey (Freitas, Oliveira, Sacol, \& Moscarola,2000; Fonseca, 2002).

A escolha pela abordagem quantitativa foi motivada pela abrangência da população da pesquisa, qual seja, os alunos efetivamente matriculados no curso de bacharelado a distância em administração pública vinculados ao PNAP. A delimitação da população foi definida a partir de informações da coordenação do PNAP na CAPES, a qual indicou que tais cursos são oferecidos em 22 estados brasileiros e no Distrito Federal. No total, são 48 Instituições de Ensino Superior - IES (35 vinculadas ao programa pelo Edital 01/2009 e 13 vinculadas pelo Edital 19/2012), localizadas em todas as regiões brasileiras, com oferta total de 36.229 vagas nos cursos de bacharelado a distância em administração pública, conforme dados do sistema de acompanhamento de cursos da UAB/CAPES (SISREL).

Diante da dificuldade de acesso presencial a todas essas instituições, a pesquisa foi viabilizada por meio de contatos virtuais. Primeiramente, realizou-se o contato via e-mail com a Coordenação Geral do PNAP, solicitando os endereços eletrônicos dos coordenadores de todas as instituições que ofertavam o curso de bacharelado em administração pública a distância. Em posse desses endereços de e-mail, foi encaminhada uma mensagem informando os objetivos e a relevância da pesquisa aos coordenadores dos cursos, solicitando-lhes a autorização para a realização da pesquisa, bem como a colaboração na divulgação e no repasse do link do questionário (hospedado no sistema LimeSurvey) aos seus alunos. Estes, por sua vez, ao tomarem conhecimento e aceitarem colaborar com a pesquisa, acessavam o link encaminhado por e-mail. Logo, o apoio dos coordenadores dos cursos foi fundamental para a realização da pesquisa.

A amostra específica envolveu 273 alunos de diferentes universidades dos estados brasileiros que ofertavam cursos de bacharelado a distância pelo PNAP: Instituto Federal de Educação Ciência e Tecnologia da Paraíba - IFPB, Universidade do Estado de Mato Grosso - UNEMAT, Universidade do Tocantins - UNITINS, Universidade Estadual de Mato Grosso do Sul - UEMS, Universidade Federal do Maranhão - UFMA, Universidade Federal da Paraíba - UFPB, Universidade Federal de Goiás - UFG, Universidade Federal de Mato Grosso do Sul - UFMS, Universidade Federal Fluminense - UFF. Nesse sentido, embora a amostra não seja puramente probabilística, mostrou-se bem heterogênea e, consequentemente, representa de maneira significativa o universo em estudo, o que permite, portanto, a operacionalização estatística empreendida.

O instrumento de coleta de dados foi o questionário autoadministrado, conhecido também como survey autoadministrado. A decisão pela utilização via internet foi fundamentada nas considerações de Freitas, Oliveira, Sacol, e Moscarola (2000), os quais destacam que elementos como custo, tempo e garantia de resposta aceitável para o estudo são fundamentais no momento da escolha da estratégia de aplicação do instrumento.

O questionário utilizado no estudo foi estruturado em duas seções. A primeira buscou levantar informações gerais sobre os sujeitos participantes da pesquisa, e a segunda identificou as características do processo de aprendizagem dos alunos de cursos de bacharelado em administração pública a distância vinculados ao PNAP, com base nos princípios andragógicos do modelo desenvolvido por Knowles, Holton e Swanson (2011).

As 12 questões da primeira seção do questionário foram apresentadas em forma de múltipla-escolha ou de questões abertas. Já as 30 assertivas da segunda seção foram respondidas com base em uma escala ordinal de 1 a 10 , cujo menor valor (1) corresponde ao "discordo plenamente" e o valor máximo (10) referese ao "concordo plenamente".

Após a elaboração do questionário e antes da sua aplicação com os sujeitos da pesquisa, foi realizado um pré-teste, com uma amostra de 30 alunos de graduação e 20 de pós-graduação em administração, objetivando-se retificar as possíveis falhas ou imprecisões na redação, tais como complexidade e desnecessidade das questões, constrangimentos para o informante, exaustão, entre outras. Após o pré-teste, foram realizadas algumas alterações, tais como substituição de palavras (substantivos e adjetivos) que ainda se apresentavam confusas e prejudicavam a interpretação dos participantes. Os resultados obtidos no pré-teste foram tabulados no software SPSS, versão 20.0, extraindo-se as medidas de frequência, histograma, assimetria e curtose. No primeiro momento, as medidas sinalizaram normalidade nas variáveis das quais extraímos a amostra, o que assegura melhores condições de análise nas técnicas selecionadas.

Realizadas a avaliação e as retificações, o questionário foi aplicado utilizando a plataforma LimeSurvey durante os meses de outubro e novembro de 2013, com o apoio de parte dos coordenadores de cursos na divulgação e incentivo à participação dos alunos na pesquisa.

Para a análise dos dados, foram utilizados testes de associação (correlação), análise de variância e fatorial. Seguindo as recomendações de Costa (2012), a análise dos dados envolveu as seguintes etapas: (a) enumeração dos questionários para facilitar o acesso, caso seja necessário rever alguma resposta; (b) tabulação dos dados; (c) análise preliminar dos dados para as medidas descritivas e os missing values; (d) avaliação da adequação da amostra, do método de extração, dos fatores, e da decisão de rotação; e, por fim, (e) exploração dos dados através das análises estatísticas.

Após a tabulação dos dados, foi realizada uma análise preliminar, na qual houve a extração de medidas descritivas e a análise dos missing values.Nesse momento, observou-se que 39 
questionários possuíam excesso de dados perdidos a ponto de inviabilizarem a análise, levando à decisão pela sua exclusão.

Ao realizar a análise fatorial exploratória, foram feitas várias combinações entre as variáveis para identificar o valor de esfericidade de Barlett e a medida de adequação amostral KaiserMeyer-Olkin (KMO), tomando como referência as recomendações de Costa (2012), ou seja, valores de 0,000 e entre 0,5 a 1,0, respectivamente. Quanto ao número de fatores, dentre as 30 variáveis referentes aos princípios andragógicos, foram excluídas quatro delas por não apresentarem aderência aos fatores gerados na pesquisa e apresentarem escores fatoriais abaixo de 0,5. As 26 variáveis deram origem a 6 fatores. Para a rotação, optou-se pelo método Varimax, uma vez que aproxima os escores das variáveis entre os extremos, facilitando as análises (COSTA, 2012). Na exploração dos dados, para atender aos objetivos dessa pesquisa, utilizaram-se medidas descritivas, análises fatoriais e ANOVA.

\section{Resultados da pesquisa}

Para alcançar o objetivo deste estudo, inicialmente foi necessário caracterizar o perfil dos respondentes da pesquisa. Observou-se que os alunos participantes realizam seus cursos de bacharelado em Administração Pública nas seguintes instituições: IFPB (5,0\%); UNEMAT (1,7\%), UNITINS (8,8\%), UEMS $(8,8 \%)$, UEMA (34,3\%), UFPB (2,5\%), UFG (2,5\%), UFMS (14,2\%) e UFF $(21,3 \%)$.

Quanto ao ano de início da oferta do curso por instituição participante do estudo, é possível observar que apenas a UFMA começou a ofertar o curso de graduação em Administração Pública no ano de 2009; quatro instituições (UNEMAT, UFG, UFMS e UFF) iniciaram o curso em 2010; a UEMS em 2012; e o IFPB, a UFPB e a UNITINS em 2013.

Em relação ao ano que iniciaram o curso, os dados revelam que grande parte dos sujeitos dessa pesquisa são alunos iniciantes, considerando que 60\% iniciaram o curso em 2012 e 2013. O quantitativo dos alunos veteranos, ou seja, que iniciaram o curso em 2009, 2010 e 2011 envolve respectivamente 8,8\%, 17,2\% e $14,2 \%$.

Após a análise das características sociodemográficas da amostra deste estudo, verificou-se que grande parte dos alunos dos cursos de graduação a distância em administração pública tem entre 25 a 40 anos (56\%), são casados ou vivem em uma união estável $(52,3 \%)$, residem com seus cônjuges (58\%), têm filhos (52,7\%), estão realizando o primeiro curso superior(62,3\%) e não possuíam familiaridade com ambientes virtuais de aprendizagem (64,4\%). A grande maioria informou que está trabalhando e que o trabalho atual não é sua primeira experiência profissional $(75,7 \%)$. Cabe ainda ressaltar a presença significativa de alunos com mais de 40 anos nessa modalidade de ensino, somando $26,6 \%$ do número total de participantes, o que corrobora com dados apresentados por Palloff e Pratt (2004), ao descrever o aluno virtual como aquele que, geralmente, tem mais de 25 anos, está empregado, podendo ser tanto do sexo masculino quanto do feminino; evidenciando, portanto, que estes cursos atendem também a um público com idade mais avançada.

Princípios andragógicos da aprendizagem em ambiente virtual

Para identificar os princípios andragógicos, foi realizada uma análise fatorial exploratória das variáveis do questionário. Os fatores que emergiram foram denominados de princípios andragógicos da aprendizagem em ambiente virtual, e cada princípio recebeu uma denominação específica para traduzir a essência do agrupamento.

Inicialmente,verificou-se a viabilidade da análise fatorial. A avaliação da significância geral da matriz foi realizada por meio do teste $\mathrm{KMO}$, obtendo-se o resultado 0,854 , e pelo teste de Esfericidade de Barlett, que ao apresentar um p-valor de 0,00 indica a adequação da análise fatorial. Atentou-se, ainda, para outras medidas de confiabilidade, dentre essas o Alpha de Cronbach, que apresentou um índice de 0,888.

Na tabela 1, é possível visualizar os seis princípios extraídos e, em cada caso, o conjunto específico de variáveis obtidas por meio da aplicação do método Varimax, além dos coeficientes de correlação entre cada fator e as variáveis agrupadas, que são as cargas fatoriais. Além disso, são apresentados os percentuais da variância explicada de cada fator,em que é possível observar que o princípio 1 é composto por oito variáveis;o princípio 2 por seis variáveis;o princípio 3 por cinco variáveis;o princípio 4 por três variáveis; e os princípios 5 e 6 por duas variáveis cada. Realizando o somatório, constata-se que os seis fatores (princípios) juntos explicam aproximadamente $65 \%$ da variância total.

Concluídas as análises iniciais, a fase posterior consistiu na denominação dos princípios. Conforme Hair Jr, Black, Babin, Anderson e Tatham (2005), essa etapa consiste em atribuir um rótulo que represente as dimensões latentes de cada fator.

Considerando-se o agrupamento efetuado pela análise fatorial e, de acordo com a fundamentação teórica do trabalho, chegou-se a seis princípios, aqui denominados como "Princípios Andragógicos da Aprendizagem em Ambiente Virtual".

O princípio 1,"Autonomia e Iniciativa no Processo de Aprendizagem",aponta características não só demandadas pela educação a distância, mas também pelo mercado de trabalho (Knowles, Holton, \& Swanson; 2011; Alves, Zambalde, \& Figueiredo, 2004; Brookfield,1986). Autonomia, capacidade de evoluir e agir de maneira autônoma, independência, responsabilidade, habilidade para solucionar problemas e comprometimento são características necessárias ao administrador e desenvolvê-las e colocá-las em prática no processo de aprendizagem é algo bastante positivo.

O segundo princípio foi denominado "Autodirecionamento no Processo de Aprendizagem". Participar ativamente de todas as etapas do processo de aprendizagem (identificação das necessidades, planejamento das atividades, identificação dos recursos necessários, execução, e avaliação das próprias experiências de aprendizagem),ou seja, assumir uma postura autodirecionada também é uma demanda do ambiente virtual. Vale 
ressaltar que os alunos autodirecionados, isto é, que se envolvem com o seu processo de aprendizagem, aprendem mais, e,por conseguinte, possivelmente serão profissionais mais preparados para servir à sociedade enquanto gestores públicos (Merriam, Caffarella, \& Baumgartner, 2006; Cranton, 2006; Moraes,Silva, \& Cunha, 2004; Candy, 1987; Brookfield, 1986). Logo, ressalta-se a dupla importância desse pressuposto.

No que se refere ao terceiro princípio "Motivação para a Aprendizagem", ressalta-se que os futuros gestores públicos, em sua maioria, revelaram que percebem a relevância do que é ensinado no curso de bacharelado a distância em Administração Pública tanto para a sua vida pessoal quanto profissional, e consideram-se motivados ao perceberem que podem adquirir um novo conhecimento no curso, pois o que aprendem pode auxiliá-los na resolução de problemas e acreditam que a aprendizagem é importante para suas vidas. Destaca-se, nesse sentido, a importância de se abordar no curso conteúdos que condizem com as práticas administrativas (Knowles, Holton, \& Swanson, 2011; Rogers, 2011; Dewey, 1973).

Tabela 1- Matriz de Correlação dos Princípios Andragógicos da Aprendizagem em Ambiente Virtual

\begin{tabular}{|c|c|c|c|}
\hline FATOR & VARIÁVEIS CORRELACIONADAS & $\begin{array}{l}\text { Carga } \\
\text { Fatorial }\end{array}$ & $\begin{array}{l}\text { Variância } \\
\text { Explicada } \\
\text { (\%) }\end{array}$ \\
\hline \multirow{8}{*}{ PRINCÍPIO 1} & Iniciativa própria no processo de aprendizagem & 0,61 & \multirow{8}{*}{15,99} \\
\hline & Capacidade de evoluir e agir de maneira autônoma & 0,68 & \\
\hline & Independência no processo de aprendizagem & 0,58 & \\
\hline & Responsabilidade pela própria aprendizagem & 0,62 & \\
\hline & Planejamento do próprio estudo & 0,73 & \\
\hline & $\begin{array}{l}\text { Habilidade para solucionar os problemas existentes no próprio processo } \\
\text { de aprendizagem }\end{array}$ & 0,65 & \\
\hline & Comprometimento com a própria aprendizagem & 0,66 & \\
\hline & Abertura a novos métodos e ferramentas de ensino & 0,57 & \\
\hline \multirow{6}{*}{ PRINCÍPIO 2} & Identificação das próprias necessidades de aprendizagem no curso & 0,67 & \multirow{6}{*}{13,03} \\
\hline & $\begin{array}{l}\text { Responsabilidade pelo planejamento das próprias atividades de } \\
\text { aprendizagem no curso }\end{array}$ & 0,67 & \\
\hline & $\begin{array}{l}\text { Responsabilidade pela execução das próprias atividades de aprendizagem } \\
\text { no curso }\end{array}$ & 0,56 & \\
\hline & $\begin{array}{l}\text { Responsabilidade pela avaliação das próprias experiências de } \\
\text { aprendizagem no curso }\end{array}$ & 0,63 & \\
\hline & $\begin{array}{l}\text { Responsabilidade pelo diagnóstico das próprias necessidades de } \\
\text { aprendizagem no curso antes de iniciar as atividades planejadas pelos } \\
\text { professores }\end{array}$ & 0,72 & \\
\hline & $\begin{array}{l}\text { Iniciativa na identificação dos recursos necessários para o meu processo } \\
\text { de aprendizagem no curso }\end{array}$ & 0,64 & \\
\hline \multirow{5}{*}{ PRINCÍPIO 3} & $\begin{array}{l}\text { Percepção da relevância do que é ensinado no curso para a sua vida } \\
\text { PESSOAL }\end{array}$ & 0,72 & \multirow{5}{*}{12,89} \\
\hline & $\begin{array}{l}\text { Percepção da relevância do que é ensinado no curso para sua vida } \\
\text { PROFISSIONAL }\end{array}$ & 0,67 & \\
\hline & $\begin{array}{l}\text { Motivação no curso ao perceber que se pode aprender um novo conteúdo } \\
\text { no curso }\end{array}$ & 0,77 & \\
\hline & $\begin{array}{l}\text { Motivação no curso ao acreditar que a aprendizagem de um novo conteúdo } \\
\text { ajudará a resolver problemas }\end{array}$ & 0,76 & \\
\hline & $\begin{array}{l}\text { Motivação no curso ao acreditar que a aprendizagem é importante para a } \\
\text { vida }\end{array}$ & 0,77 & \\
\hline \multirow{3}{*}{ PRINCÍPIO 4} & Aplicação da aprendizagem na resolução de um problema & 0,89 & \multirow{3}{*}{9,83} \\
\hline & Aplicação da aprendizagem na execução de uma tarefa. & 0,87 & \\
\hline & Aplicação da aprendizagem nas situações diárias & 0,68 & \\
\hline \multirow{2}{*}{ PRÍNCIPIO 5} & $\begin{array}{l}\text { Necessidade de suporte, ou seja, necessidade de apoio afetivo de } \\
\text { terceiros (professores, tutores) }\end{array}$ & 0,86 & \multirow[t]{2}{*}{6,77} \\
\hline & $\begin{array}{l}\text { Necessidade de direção, ou seja, necessidade de assistência por outra } \\
\text { pessoa no processo de aprendizagem }\end{array}$ & 0,84 & \\
\hline \multirow{2}{*}{ PRINCÍPIO 6} & Liberdade de escolher em fazer ou não as atividades do curso & 0,78 & \multirow{2}{*}{6,36} \\
\hline & Liberdade de escolher e decidir o que irá estudar no curso & 0,80 & \\
\hline
\end{tabular}

Método de Extração: Análise de Componentes Principais a partir do Software SPSS, versão 20.0.

Método de Rotação: Varimax com normalização de Kaiser. 
Fonte: Autores, 2016.

Quanto ao Princípio 4, denominado "Utilidade da Aprendizagem", foi possível observar que os alunos virtuais de administração pública associam a utilidade da aprendizagem a sua aplicação na resolução de um problema, na execução de uma tarefa e nas situações diárias, o que demanda a necessidade de uma abordagem de ensino que explore mais as experiências dos alunos e promova relação com a prática (Rogers, 2011; Knowles,Holton, \& Swanson, 2011;Le Boterf, 2003;Dewey, 1973).

Sobre o quinto princípio "Orientação e Apoio para a Aprendizagem", verificou-se que, em alguns momentos, os alunos de administração pública precisam de suporte e direção no processo de aprendizagem. No entanto, o fato deles apresentarem essas necessidades em situações específicas não significa que não possuam autodirecionamento. De todo modo, é preciso desenvolver estratégias e recursos que busquem minimizar essa fragilidade na $\mathrm{EaD}$, já que alunos com predominância dessas características tendem a não se adequar, podendo constituir-se como um dos fatores que contribuem para a grande evasão de alunos nessa modalidade.

No que se refere ao princípio 6, intitulado "Maturidade no Processo de Aprendizagem", foi possível perceber que,embora os alunos possuam autonomia e maturidade, as experiências vivenciadas em cursos ofertados na modalidade a distância, em geral, possuem um formato padronizado e menos flexível que os cursos presenciais. Isso contribui para dificultar o desenvolvimento de uma postura mais ativa e participativa em termos de direcionamento do processo de aprendizagem. Para minimizar esse problema, destaca-se a importância da utilização de uma metodologia que possibilite abertura para os alunos adequarem seu processo de aprendizagem a sua forma particular de estudar e aprender.

Além da metodologia, torna-se relevante compreender que o processo de aprendizagem envolve a construção do conhecimento como um processo individual, um processo experiencial de aprendizagem ativa, cooperativa, que considere o papel do contexto e a natureza intrínseca da avaliação. Esses fatores são apontados por Sannia, Ercoli e Leo (2009) como determinantes em um paradigma construtivista da aprendizagem. Os autores realizaram um estudo sobre a utilização da educação a distância no processo de treinamento de servidores públicos e propõem um framework para avaliação do processo com cinco dimensões: a) critérios para avaliação de um ambiente virtual de aprendizagem; b) a qualidade dos sistemas de comunicação; c) a qualidade dos serviços técnicos e didáticos; d) a qualidade do sistema de gestão e; e) a qualidade dos objetos de aprendizagem.

Apesar do estudo ser direcionado para o campo da qualificação de servidores públicos, considera-se que os princípios andragógicos da aprendizagem em ambiente virtual propostos neste estudo podem contribuir para o desenvolvimento e capacitação de servidores públicos porque apresenta fatores intimamente ligados ao comportamento do aprendiz.

\section{Fatores mediadores do processo de aprendizagem em ambiente virtual}

Para identificar os fatores mediadores da aprendizagem em ambiente virtual, foi realizada uma análise de correlações entre os princípios andragógicos e alguns dados sociodemográficos,com o propósito de verificar se há diferenças significativas entre os princípios e o gênero, o período, a idade, a experiência profissional, o fato de ter ou não filhos, a familiarização com o ambiente virtual de aprendizagem e a formação acadêmica. A tabela 2 apresenta a análise dos dados gerados após a realização da Análise de Variância - ANOVA, evidenciando as correlações mais significativas.

Tabela 2 - Correlação entre os princípios e variáveis sociodemográficos

\begin{tabular}{|c|c|c|c|c|c|c|c|c|c|c|c|c|c|c|}
\hline \multirow{2}{*}{ Princípios } & \multicolumn{2}{|c|}{ Gênero } & \multicolumn{2}{|c|}{ Período } & \multicolumn{2}{|c|}{ Idade } & \multicolumn{2}{|c|}{$\begin{array}{l}\text { Experiência } \\
\text { Profissional }\end{array}$} & \multicolumn{2}{|c|}{ Filhos } & \multicolumn{2}{|c|}{$\begin{array}{c}\text { Familiariza-ção com o } \\
\text { AVA }\end{array}$} & \multicolumn{2}{|c|}{$\begin{array}{l}\text { Formação } \\
\text { Acadêmica }\end{array}$} \\
\hline & $\mathbf{F}$ & Sig & $\mathbf{F}$ & Sig & $\mathbf{F}$ & Sig & $\mathbf{F}$ & Sig & $\mathbf{F}$ & Sig & $\mathbf{F}$ & Sig & $\mathbf{F}$ & Sig \\
\hline 1 & 0,14 & 0,70 & 2,50 & $0,02^{\star *}$ & 2,99 & $\underset{\star \star *}{0,02}$ & 2,39 & $\underset{*}{0,07}$ & 3,52 & $\underset{*}{0,06}$ & 4,65 & $\underset{\star *}{0,03}$ & 5,37 & 0,02 \\
\hline 2 & 0,80 & 0,37 & 1,38 & 0,21 & 1,11 & 0,35 & 1,72 & 0,16 & 0,18 & 0,67 & 2,81 & 0,09 & 0,30 & 0,59 \\
\hline 3 & 0,00 & 0,97 & 1,93 & $\underset{*}{0,06}$ & 1,38 & 0,24 & 1,88 & 0,13 & 2,87 & $\underset{*}{0,09}$ & 0,52 & 0,47 & 0,14 & 0,71 \\
\hline 4 & 0,34 & 0,56 & 1,66 & 0,12 & 0,96 & 0,43 & 0,17 & 0,91 & 1,35 & 0,24 & 2,66 & $\underset{*}{0,10}$ & 0,20 & 0,65 \\
\hline 5 & 0,06 & 0,81 & 1,90 & $0,07^{*}$ & 2,09 & $\underset{*}{0,08}$ & 1,36 & 0,25 & 0,47 & 0,49 & 9,75 & $\underset{\star *}{0,00}$ & 5,01 & $\underset{* *}{0,03}$ \\
\hline 6 & 4,46 & $0,04^{* *}$ & 1,75 & $\underset{*}{0,10}$ & 2,53 & $0,04^{* *}$ & 1,47 & 0,22 & 0,07 & 0,79 & 0,14 & 0,71 & 0,00 & 0,96 \\
\hline
\end{tabular}

*Moderada Correlação $(0,05<p<0,10)$ **Forte Correlação (Forte $p<=0,05$ )

Fonte: Autores (2016).

Os dados apresentados na tabela 3 apontam que há diferenças significativas entre o tipo de gênero e o Princípio 6, que se refere à
"Maturidade no Processo de Aprendizagem", com nível de significância de 0,04.As particularidades existentes em homens e 
mulheres, inclusive no que se refere às distintas experiências vivenciadas por ambos, proporcionam diferentes modos de agir, perceber, interagir e se comportar que interferem no processo de aprendizagem. Assim, não é estranho que alunos do gênero feminino e masculino apresentem posturas diferentes em relação à liberdade de escolher fazer ou não as atividades do curso e de decidir o que irão estudar. No estudo realizado por Raemdonck, Van der Leeden, R., Valcke, M., Segers, M., Thijssen(2012) sobre fatores preditores da aprendizagem autodirigida, o fator gênero é apontado como determinante. Os autores consideram que as mulheres deveriam ser mais orientadas para a aprendizagem no desenvolvimento da carreira em comparação com os homens, que adotam comportamentos de auto apresentação e mais orientados para os relacionamentos.

Os demais princípios não apresentaram relações significativas com essa variável, demonstrando que não há diferenças relacionadas ao gênero quanto à autonomia, à iniciativa e ao autodirecionamento no processo de aprendizagem; à percepção sobre a motivação e a utilidade da aprendizagem; e à necessidade de orientação e apoio para a aprendizagem.

No que se refere ao período do curso, observou-se que há forte correlação entre essa variável e o Princípio 1 -Autonomia e Iniciativa no Processo de Aprendizagem, com nível de significância de 0,02 . Conforme apontam os resultados, a iniciativa própria, a capacidade de evoluir e agir de maneira autônoma, a independência, a responsabilidade e o planejamento pelo próprio estudo, a habilidade para solucionar os problemas existentes no processo de aprendizagem, o comprometimento e a abertura a novos métodos e ferramentas de ensino diferem entre alunos iniciantes e alunos veteranos.

Constatou-se, ainda, moderada correlação entre a variável período do curso e o Princípio 3 - Motivação para a Aprendizagem, o Princípio 5 - Orientação e Apoio para a Aprendizagem e o Princípio 6 - Maturidade no Processo de Aprendizagem, com níveis de significância de $0,06,0,07$ e 0,10, respectivamente.Nesse sentido, destaca-se que alunos iniciantes e veteranos apresentam diferenças também na percepção sobre a relevância do que é ensinado no curso para sua vida pessoal e profissional, e na motivação no curso, além de apresentarem posturas diferentes no que se refere à necessidade de suporte e direção no processo de aprendizagem.

Os resultados indicam, ainda, que há relações significativas entre período e os princípios 1, 3, 5 e 6. Os demais princípios não apresentaram relações significativas, revelando que não há diferenças relacionadas a essa variável envolvendo a utilidade da aprendizagem, a maturidade e o autodirecionamento no processo de aprendizagem.

Outra variável significativa se refere à faixa etária. $\mathrm{A}$ análise revela que há relação significativa dessa variável com o Princípio 1 - Autonomia e Iniciativa no Processo de Aprendizagem e com o Princípio 6 - Maturidade no Processo de Aprendizagem, apresentando, respectivamente, níveis de significância de 0,02 e 0,04 , que apontam forte correlação. A variável apresentou ainda moderada relação com o Princípio 5 - Orientação e Apoio para a Aprendizagem, com nível de significância de 0,08. Raemdonck et al (2012) destacam que fatores demográficos como idade e gênero exercem um papel significativo na aprendizagem autodirigida. Pessoas mais velhas podem ter um nível de autodirecionamento em relação à aprendizagem maior porque vivenciaram mais experiências.

Os resultados ratificam o que Knowles, Holton e Swanson (2011) defendem ao tratar da teoria de aprendizagem de adultos. Conforme os autores, o grau de dependência de um indivíduo varia de acordo com o seu desenvolvimento cronológico, ou seja, à medida que o indivíduo amadurece, o seu grau de dependência diminui, o que resulta em uma maior necessidade de desenvolver a autonomia e a iniciativa no processo de aprendizagem.

De acordo com Mezirow (1991), não há um estabelecimento de idade mínima que defina o nível de independência do aprendiz. No entanto, define-se como aluno independente aquele que possui capacidade de assumir os seus atos. Conforme Knowles, Holton e Swanson (2011), a autonomia, a iniciativa e a maturidade no processo de aprendizagem começam a se desenvolver já no início da adolescência e crescem à medida que os indivíduos amadurecem biologicamente, frequentam a escola, assumem responsabilidades e trabalham.

Analisando as possíveis correlações entre as variáveis "experiência profissional" e "filhos" e os seis princípios, constataram-se apenas moderadas correlações entre ambas e o Princípio 1. A variável experiência profissional apresentou correlação com nível de significância de 0,07 , e o fato de ter ou não filhos apresentou correlação com nível de significância de 0,06. A variável referente a "filhos" apresentou também moderada correlação com o Princípio 3 - Motivação para a Aprendizagem.

Outras variáveis que merecem destaque são a"familiarização com ambiente virtual" e a "formação acadêmica", já que ambas apresentaram fortes correlações com osPrincípios 1 e 5 . Constatouse que há relação entre "familiarização com ambiente virtual" e o Princípio 1, com nível de significância de 0,03, e o Princípio 5, com nível de significância de 0,00 . Já a relação entre a variável "formação acadêmica" e os Princípios 1 e 5 apresentaram níveis de significância de 0,02 e 0,03, respectivamente. Verificou-se ainda moderada correlação entre a variável "familiarização com ambiente virtual" e os Princípios 2 e 4, com níveis de significância de 0,09 e 0,10 , respectivamente.

Os dados apontam que o fato de o aprendiz já ter vivenciado alguma experiência em ambiente virtual ou já ter realizado outro curso superior anteriormente interfere na autonomia e iniciativa desse aluno em seu processo de aprendizagem, bem como na necessidade de orientação e apoio. Conforme Knowles, Holton e Swanson (2011) e Cranton (2006), as experiências vivenciadas pelo indivíduo serão responsáveis pelo amadurecimento e pela construção da autonomia do aprendiz.

No que se refere ao princípio Autodirecionamento no Processo de Aprendizagem, o estudo indicou que não há nenhuma forte correlação entre os dados sociodemográficos (gênero, faixa etária, 
estado civil, o fato de ter filhos ou ter vivenciado experiências profissionais) e esse princípio, assim como também não foram verificadas fortes correlações entre essas variáveis e os Princípios 3 - Motivação para a Aprendizagem e 4 - Utilidade da Aprendizagem.

Os resultados da ANOVA revelaram a existência de fatores mediadores que podem exercer influência positiva ou negativa sobre o processo de aprendizagem. Essa discussão é apresentada por autores como Silva (2009), Souza (2004), Silva, Godoi e Rambo (2003), Antonacopoulou e Gabriel (2001) e Merriam e Cafarella (1991). Conforme Silva (2009), existe uma série de fatores que podem facilitar ou dificultar os processos de aprendizagem. Merriam e Caffarella (1991) destacam que é de grande importância compreender os fatores mediadores e como eles interferem no processo de aprendizagem. A figura 1 caracteriza o processo de aprendizagem em ambiente virtual e envolve os princípios andragógicos e os fatores mediadores da aprendizagem dos aprendizes adultos em ambientes virtuais.

Figura 1 - O Processo de Aprendizagem em Ambiente Virtual

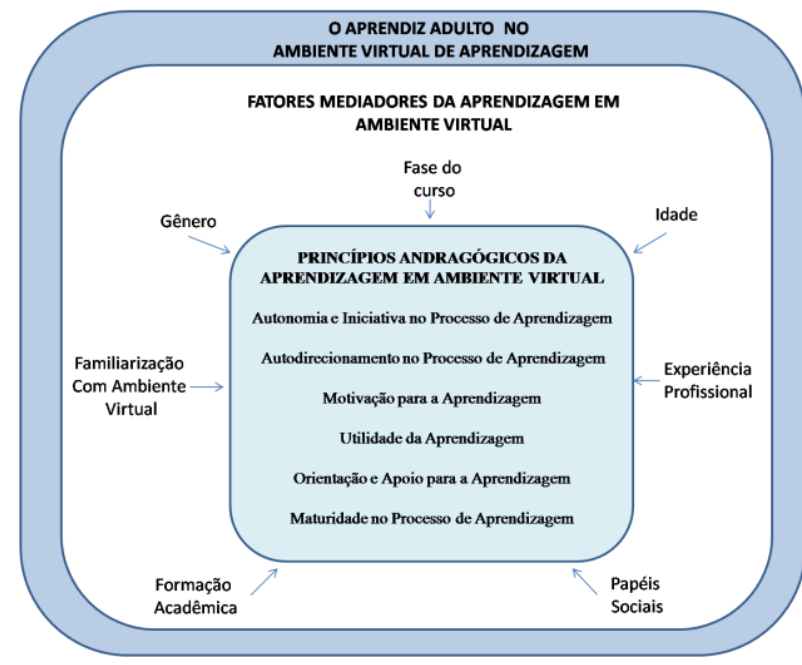

Fonte: Autores (2016)

A partir da identificação dos fatores mediadores do processo de aprendizagem em ambiente virtual associados ao perfil do aluno adulto, conclui-se que princípios andragógicos dessa modalidade de ensino sofrem influência de fatores como gênero, fase do curso, idade, experiência profissional, papéis sociais, formação acadêmica e familiarização com o ambiente virtual de aprendizagem, que podem facilitar ou inibir a aprendizagem em ambiente virtual. Estudo realizado por Raemdonck et al (2012) também constatou a relação entre fatores sócio demográficos e aprendizagem autodirigida, o que ratifica uma das contribuições deste trabalho para entender a dinâmica do processo de aprendizagem em ambiente virtual. Outro estudo realizado por Rashid e Asghar (2016) envolvendo o uso de tecnologia na aprendizagem autodirigida identificou correlação positiva entre a adoção de tecnologia e o engajamento dos estudantes. No contexto da educação a distância, o engajamento do estudante é determinante para o seu desempenho, o que ratifica a relevância dos Princípios
Andragógicos da Aprendizagem em Ambiente Virtual para entender a dinâmica dos processos de aprendizagem dos alunos.

Partindo da premissa de que homens e mulheres possuem particularidades, ou seja, características e necessidades diferentes, o gênero é um mediador que tanto pode contribuir com o processo de aprendizagem quanto pode limitá-lo.

De modo semelhante, a fase do curso em que se encontra o aluno também é visualizada como um fator mediador, pois os alunos iniciantes apresentam características diferentes se comparadas ao perfil de alunos já na fase final do curso. Assim, o fato do aluno ser iniciante, veterano ou concluinte também influencia positiva ou negativamente no processo de aprendizagem.

Outro fator apontado nesse estudo como mediador é a faixa etária do aluno. Entende-se que alunos mais jovens apresentam características diferentes dos alunos mais velhos, as quais também exercem influência no processo de aprendizagem. Esse fator não se refere apenas ao desenvolvimento cronológico, mas sim ao desenvolvimento social, isto é, as experiências vivenciadas pelo aluno por ter mais idade são determinantes no processo de aprendizagem.

A experiência profissional também desenvolve no aluno aprendiz uma postura mais autônoma e independente, que caracteriza a sua maturidade. Logo, alunos que já trabalharam apresentam um perfil diferente daqueles que nunca trabalharam. Essa variável também é um fator mediador no processo de aprendizagem dos alunos virtuais.

Quanto aos papéis sociais, entende-se que o aluno que já se encontra casado, reside com um cônjuge e não mais com os pais, possui filhos, ou seja, vivencia papéis sociais mais intensos apresentam características diferenciadas daqueles que ainda não vivenciaram essas experiências. Assim, os papéis sociais também são vistos como um fator mediador no processo de aprendizagem, uma vez que vivenciar ou não essas experiências podem promover ou limitar a aprendizagem.

Por fim, o processo de aprendizagem em ambiente virtual sofre ainda influência de fatores associados às experiências de educação formal, ou seja, o fato de um aluno já possuir uma formação acadêmica ou familiaridade com o ambiente de aprendizagem tanto pode contribuir positiva quanto negativamente no processo, dependendo de como essas experiências ocorreram, ou seja, se foram bem ou mal sucedidas, prazerosas ou padecedoras. Entende-se, dessa forma, que as experiências vivenciadas pelo aprendiz, sejam profissionais, sociais ou de educação formal, exercem influência na aprendizagem em ambiente virtual, podendo ser tanto propulsoras quanto inibidoras.

$\mathrm{Na}$ década de 1980, já se visualizava a relevância desses pressupostos no processo de aprendizagem de alunos universitários. Eckstein (1982) enfatizava que, devido à inexistência de uma formação didática específica, os professores do nível superior de ensino lecionava sem o conhecimento prévio dos pressupostos psicológicos, didáticos e sociais relacionados ao aprendizado, induzindo ao que ele denominou de "visão míope". Apesar dos avanços recentes na qualificação do corpo docente, 
grande parte dos professores continuam desatentos a esses aspectos e replicam os padrões intuitivos e as abordagens tradicionais.

Considerando o ensino em Administração, Pimenta e Anastaisou (2002) enfatizam a predominância do ensino expositivo e a passividade do aluno na interação em sala de aula. Lima e Silva (2012) revelam questões acerca do papel do docente na aprendizagem do discente, do incentivo pela prática reflexiva e crítica, e da maturidade e aprendizado emancipatório do aluno de administração, ao caracterizar as perspectivas de aprendizagem utilizadas pelos docentes no ensino de disciplinas de formação profissional no curso de Administração da Universidade Federal da Paraíba. Com base nesse estudo, Lima e Silva (2013) constataram que os de Administração não tiveram uma formação acadêmica consistente envolvendo os pressupostos e perspectivas teóricas da aprendizagem de adultos, o que pode dificultar a introdução de uma abordagem balizada pela andragogia e pela aprendizagem autodirecionada e transformadora. Além disso, verificou-se outros fatores impactantes na condução da sua ação profissional, tais como: 1) a estrutura da universidade é defasada para o uso de estratégias de ensino a partir de uma visão construtivista; 2) o apoio do Governo ainda é bem limitado, devido à carência de políticas públicas voltadas para a qualidade do ensino; e 3) a falta de compromisso do aluno e o seu interesse em participar desse processo, embora os docentes reconheçam a relevância da adoção de metodologias andragógicas na formação de administradores.

No contexto da educação a distância, Silva e Ramos (2011) destacam que o Ambiente Virtual de Aprendizagem (AVA) potencializa a autonomia e autodirecionamento do estudante. As autoras destacam que, nesses ambientes, professores e estudantes possuem papeis diferenciados do ensino presencial, e que a autonomia - enquanto atributo do aprendiz - deve ser construída e ressignificada ao longo de sua vida para a sua formação profissional e pessoal. No entanto, o desenvolvimento da autonomia está associado às metodologias e didáticas utilizadas no AVA, assim como à forma como as ações e o ambiente são planejados (Silva; Ramos, 2011).

\section{Considerações Finais}

Os princípios andragógicos identificados no estudo revelam como os alunos no ambiente virtual têm autonomia, autodirecionamento e apresentam níveis de independência enquanto sujeitos em processo de formação e de desenvolvimento de competências, o que indica a necessidade de pensar a formação profissional não apenas a partir de uma dimensão técnica, mas também de considerar que o curso contribui para a formação de cidadãos que atuarão não apenas no contexto profissional, mas no ambiente social.

Os fatores mediadores da aprendizagem envolvem um processo de desenvolvimento pessoal que está intimamente ligado à experiência, pois são as experiências passadas que determinam se os alunos estarão mais abertos à mudança e interessados em aprender, ou se caracterizam como resistentes ou desinteressados no processo de aprendizagem.

No entanto, embora os alunos de Administração da EAD apresentem esse perfil, surge uma reflexão: será que essas características são bem aproveitadas no processo de aprendizagem no ambiente virtual? Até que ponto a formação em Administração explora a capacidade de reflexão e a criticidade que esses aprendizes adultos possuem?

É comum encontrar nas instituições de ensino superior o que Paulo Freire (1987) denomina de "educação depositária", ou seja, um sistema de imposição de conteúdos e de conhecimentos, avaliações e cobranças autoritárias em que o professor é detentor máximo do saber, e o aluno, por sua vez, é um recipiente onde se deposita conteúdos programáticos. Todavia, um processo de formação, principalmente voltado a alunos adultos, deve permitir que 0 aprendiz seja capaz de interferir no processo de aprendizagem com base nas suas necessidades e com liberdade de refletir e criticar (Freire, 2003). Tratando-se de um curso voltado à formação de administradores, esses aspectos merecem ainda mais atenção, tendo em vista que a reflexão e a criticidade são essenciais ao profissional no exercício de suas funções como planejamento, controle, organização e direção. Bennisand O'Toole (2005) argumentam que a necessidade da incorporação do ensino crítico nas escolas de negócios está baseada nas necessidades intrínsecas da área. Para eles, é imprescindível que haja ênfase na formação de habilidades necessárias ao pensamento crítico indispensável à prática e à tomada de decisão.

O desenvolvimento do autodirecionamento, além de otimizar o processo de aprendizagem, contribui positivamente na atuação profissional desses aprendizes enquanto gestores, considerando que, ao exercerem atividades de gestão, tomarão decisões em diversas situações, que demandam atitudes como iniciativa e autonomia. Portanto, o ensino em Administração, de um modo geral (na modalidade presencial ou virtual), deve promover condições libertadoras para impulsionar a autonomia e desenvolver um senso de autocapacitação (Mezirow, 1991). Como resultado, pode-se ter alunos aptos a interagir no meio social, a compreender o mundo, e agir como agentes de transformação organizacional e social.

De forma conclusiva, pode-se afirmar que este estudo atingiu os objetivos a que se propôs. Em contrapartida, não ficou isento de limitações, dentre as quais se destacam: (a) a dificuldade de acesso aos alunos virtuais de Administração, tendo em vista que nem todos os coordenadores dos cursos a distância de Administração Pública se interessaram em contribuir com a pesquisa atuando como agentes intermediadores no processo de coleta de dados; (b) o longo período de tempo para se atingir um número significativo de respondentes, em virtude da baixa participação inicial dos alunos na pesquisa, que gerou a necessidade da coleta de dados demorar cerca de três meses, atrasando a conclusão do estudo; e, por fim, (c) a necessidade de outros estudos tentarem selecionar amostras mais próximas do padrão probabilístico, embora a amostra deste estudo tenha se caracterizado como heterogênea e representativa. 
É pertinente ressaltar ainda que, além dos fatores mediadores abordados nesse estudo, existem outros aspectos que merecem atenção, uma vez que a educação de adultos possui fatores mediadores contextuais, tais como as estratégias de ensino utilizadas no curso, os recursos utilizados no processo de aprendizagem, a relação do aluno com o professor e o tutor, entre outros, que podem ser objeto de investigações futuras.

Como sugestões para futuras pesquisas, recomenda-se a abordagem dos princípios andragógicos e as diferenças individuais dos alunos de Administração na modalidade presencial. A realização de um estudo dessa natureza pode permitir uma avaliação comparativa dos aspectos abordados nesta pesquisa em contextos diferentes. Por fim, sugere-se ainda a realização de estudos que relacionem os princípios andragógicos com os estilos de aprendizagem de alunos de Administração e com o contexto social dos participantes, tanto na modalidade presencial quanto na virtual.

\section{Referências}

Alves, R. M., Zambalde, A. L., \& Figueiredo, C. X. (2004). Ensino a distância. Lavras: UFLA, FAEPE.

Antonacopolou, E. P., \& Gabriel, Y. (2001). Emotion, learning and organizational change: towards an integration of psyco-analytic and other perspective. Journal of Organizational Change, (v. 14, n. 5), p. 435-451.

Argyris, Chris. (1982). Reasoning, learning and action: individual and organizational. San Francisco: Jossey-Bass.

Bennis, W. G., \&O'toole, J. (2005). How business schools lost their way. Harvard Business Review, (v. 83, n. 5), p. 96-105.

Brandão, J. M. F. (2014). Princípios Andragógicos e Fatores Mediadores da Aprendizagem na Educação a Distância em Administração Pública. (Dissertação - Mestrado) - UFPB/CCSA - João Pessoa, $193 f$.

Brandão, J. M. F.; Cavalcante, E. D. C.; \&Temoteo, J. A. G. (2014) O Processo de Aprendizagem de Alunos de Turismo e Hotelaria Sob a Perspectiva Andragógica. RBTUR - Revista Brasileira de Pesquisa em Turismo. São Paulo, 8(3), pp. 531-551, set./dez.

Brookfield, S. D. (1986) Understanding and facilitating adult learning: a comprehensive analysis of principles and effective practices. San Francisco: Jossey-Bass.

Brookfield, S. D. (1987). Reframing research into 'self-direction' in adult education: a constructivist perspective. (Tese - Doutorado). Universityof British Columbia, Ottawa.

Cavalcanti, R. A. de (1999). Andragogia: aprendizagem nos adultos. Revista de Clínica Cirúrgica da Paraíba, (6), Ano 4, 36-41.

Cieglinski, A. (2015). Educação a distância já responde por quase 15\% das matrículas no ensino superior. Agência Brasil, 07 nov. 2011. Disponível em: <http://memoria.ebc.com.br/agenciabrasil/noticia/2011-11-07/educacaodistancia-ja-responde-por-quase-15-das-matriculas-no-ensino-superior>. Acesso em: 12 out.

Coll, C., e Monereo, C. (2010). Psicologia da Educação Virtual. Aprender e Ensinar com as tecnologias da informação e comunicação. Porto Alegre, Artmed.

Costa, F. J. (2012). A análise exploratória de dados: uma abordagem moderna. Mimeografado. João Pessoa.

Cranton, P. (2006). Understanding and promoting transformative learning: aguide for educators of adults. SecondEdition. San Francisco: Jossey-Bass.

Demarco, D. J. (2013) Um balanço do Programa Nacional de Formação em Administração Pública (PNAP) como estratégia de fortalecimento da gestão pública: ocaso da Escola de Administração da UFRGS. In: Congresso de Gestão Pública, 6, Brasília. Anais...Brasília: Centro de Convenções Ulysses Guimarães.

Dewey, J. (1973). Vida e educação. (Tradução de Anísio Teixeira). São Paulo: Melhoramentos.

Eckstein, B. (1982). Ensino superior: uma introdução prática. São Paulo: Pedagógica e Universitária.

Ferraz, S. F.S., Lima, T. C.B., \& Silva, S. M. O. (2004). Contratos de aprendizagem: princípios andragógicos e ferramenta de gestão da aprendizagem. In: Encontro da Associação Nacional de Programas de PósGraduação em Administração-ENANPAD, 28., 2004, Salvador. Anais... Salvador: ANPAD, 2004. 1 CD-ROM

Fonseca, J. J. S. (2002). Metodologia da pesquisa científica. Fortaleza: UEC. Freire, P. (1987). Pedagogia do oprimido. 27.ed. Rio de Janeiro: Paz e Terra.
Freire, P. (2003). Pedagogia da autonomia- saberes necessários à prática educativa. Rio de Janeiro: Paz e Terra.

Freitas, H., Oliveira, M., Sacol, A. Z., \&Moscarola, J. (2000) O método de pesquisa survey. Revista de Administração, São Paulo, v. 35, n.3, p. 105-112, jul./set.

Gil, A. C. (2007). Como elaborar projetos de pesquisa.(4. Ed). São Paulo: Atlas.

Hair Jr, J. F, Black, W. C., Babin, B. J., Anderson, R. E., \& Tatham, R. L. (2005). Análise multivariada de dados. Porto Alegre: Bookman.

James-Gordon, Y.; Young, A.; \& Bal, J. (2003). External environment forces affecting e-learning providers. Marketing Intelligence e Planning, (v.21, n.3).

Jarvis, P. (2006). Towards a comprehensive theory of human learning: lifelong learning and the learning society. New York: Routledge.

Knowles, M. S. (1975). Self-directed learning: aguide for learners and teachers. Englewood Cliffs: Prentice Hall.

Knowles, M. S. (1980). The modern practice of adult education.from pedagogy to andragogy. Cambridge: Adult Education.

Knowles, M. S., Holton, E. F. \& Swanson, R. A. (2011). The adult learnerthe definitive classic in adult education and human resource development (7th edition). London: Elsevier.

Kolb, D. (1984). Experiential learning: experience as the source of learning and development. EnglewoodCliffs: Prentice Hall.

Laruccia, M. M., Almeida, R., \& Ruiz, T. T. (2010). O desenvolvimento das habilidades e competências profissionais de um grupo de estudantes de Administração. Inter Science Place: Revista Científica Internacional, (ano 3, n. 11), jan./fev.

Le Boterf, G. (2003). Desenvolvendo a competência dos profissionais. Porto Alegre: Artmed.

Lima, T. B. L; Silva, A. B. (2013). Difusão das perspectivas teóricas da aprendizagem na formação de administradores. REICE. Revista Iberoamericana sobre Calidad, Eficacia y Cambio en Educación, 11(3), 530.

Merriam, S. B., Caffarella, R. S. (1991). Learning adulthood: a comprehensive guide. San Francisco: Jossey-Bass.

Merriam, S., Caffarella, R., \& Baumgartner, L. (2006). Learning in adulthood (3rd ed.). San Francisco: John Wiley e Sons.

Mezirow, J. (1991). Learning to think like an adult: core concepts of transformative learning. In: MEZIROW, Jack et al. Learning as transformation critical perspectives on a theory in progress. San Francisco: Jossey-Bass.

Mezirow, J. (1985) A critical theory of self-directed learning. In: BROOKFIELD, Stephen (Ed.).Self-directed learning: from theory to practice.San Francisco: Jossey-Bass, p.17-30.

Moraes, L. V. S., Silva, M. A., \&. Cunha, C. J. C. A. (2004). A dinâmica da aprendizagem gerencial em um hospital. Revista de Administração de Empresas, (v. 3, n.2) art. 18, jul/dez. Disponível em: <http://www.rae.com.br/eletronica/index.cfm>. Acesso em: 27 set. 2014. Palloff, R. M. E., \& Pratt, K. (2004). O aluno virtual. $1^{\frac{a}{a}}$ ed. São Paulo: Artemed. Pimenta, S. y Anastasiou, L. (2002). Docência no Ensino Superior. São Paulo: Cortez.

Raemdonck, I., Van der Leeden, R., Valcke, M., Segers, M., Thijssen, J. (2012). Predictors of self-directed learning for low-qualified employees: a multi-level analysis. European Journal of Training and Development, 36 (6), pp. 572-591.

Rashid, T., Asghar, H.M. (2016). Technology use, self-directed learning, student engagement and academic performance: Examining the interrelations. Computers in Human Behavior, 63, pp.604-612.

Reymão, G. (2015). A educação à distância - EaD. s/d. Disponível em: shttp://www.crapa.org.br/artigos-detalhes.asp?codigo=421>. Acessoem: 12 out.

Rogers, C. R. (1969). Freedom to learn. Columbus: Merrill.

Rogers, J. (2011). Aprendizagem de adultos: fundamentos para educação corporativa. Porto Alegre: Artmed.

Sampieri, R. H., Collado, C. F., \& Lucio, P. B. (1991). Metodología de la investigación. México: Mcgraw Hill.

Sannia, M., Ercoli, G., Leo, T. (2009, Feb.) Evaluation of a Virtual Learning Environment for the Professional Training in Public Administration. International Journal of Advanced Corporate Learning - iJAC, 2 (1), 50-55.

Schnitman, I. (2011, março). A mediação pedagógica e o sucesso de uma experiência educacional on-line. ETD - Educ. Tem. Dig., Campinas, (v.12, n.esp.), p.287-314.

Schön, D. (1987). Educating the reflective practitionertoward a new design for teaching and learning in the professions. San Francisco: Jossey-Bass.

Silva, A. B. (2009). Como os gerentes aprendem?. São Paulo: Saraiva.

Silva, A. B., Godoi, C. K., \&Rambo, J. A. M. (2003). Fatores individuais e organizacionais associados à aprendizagem dos gerentes de uma instituição de ensino. In: Seminário Latino-lberoamericano de Gestión Tecnológica Altec, X., Ciudad de México, Anais...Ciudad de México.

Silva, A. R. M, Domingues, M. J. C. S. (2010). Atributos de retenção no ensino a distância na perspectiva dos alunos. In: Colóquio Internacional sobre Gestión Universitaria em América Del 
Sur, X., Mar del Plata, Anais... Mar del Plata: CIGU.

Silva, G. J., Ramos, W. (2011). O ambiente virtual de aprendizagem (AVA) como potencializador da autonomia do estudante: estudo de caso na UABUNB. Revista Iberoamericana de Evaluación Educativa, 4 (2), 92-106.

Smith, M. K. (2002). Malcolm Knowles, informal adult education, self-direction and andragogy. The encyclopediaof informal education. 2002. Disponível em: <www.infed.org/thinkers/et-knowl.htm>. Acesso em: 31 ago. 2011.
Soares, V. B.; Castro, D. C. (2012). Ou Isto ou Aquilo? A Integração entre Pesquisa Qualitativa e Quantitativa em Estudos Organizacionais no Brasil. In Encontro da Divisão de Estudos Organizacionais - EnEO, (7., 2012), Curitiba. Anais...Curitiba: ANPAD, 1 CD-ROM.

Souza, Y. S. (2004). Organizações de aprendizagem ou aprendizagem organizacional. Revista de Administração de Empresas, v.3, n.1, Art.5, jan./jun. 